\title{
Days to weeks of syn-eruptive magma interaction: high-resolution geochemistry of the 2002-03 branched eruption at Mount Etna
}

\author{
*Ruadhan MageE ${ }^{1}$ TeResa UBIDE ${ }^{1}$ JOHN \\ CAULFIELD $^{1,2}$
}

${ }^{1}$ School of Earth and Environmental Sciences, The University of Queensland, 4072, QLD, Australia. (*correspondence: ruadhan.magee@uq.edu.au)(t.ubide@uq.edu.au)

${ }^{2}$ Central Analytical Research Facility, Institute for Future Environments, Queensland University of Technology, 4000, QLD, Australia (j.caulfield@qut.edu.au)

The landmark Mt Etna eruption of 2002-03 provides a unique opportunity to explore magma transport and evolution through complex, well documented volcanic activity. Two distinct types of magma erupted simultaneously on the northeast and southern flanks of the volcano, respectively: those which drained the crystal-rich, central-conduit magma reservoirs (1-6 km) and those which tapped directly into deep reservoirs $(>10 \mathrm{~km})$ through 'eccentric' pathways that brought undegassed magma to the surface, generating highly explosive events. In this study, high-resolution temporal changes in melt chemistry (groundmass fraction) and mineral zoning (X-ray fluorescence mapping) track the evolution and interaction of erupted products on timescales of days to weeks. In the earliest stages of activity, melt erupted on the southern flank was relatively rich in $\mathrm{MgO}, \mathrm{CaO}, \mathrm{Cr}, \mathrm{Ni}$, and radiogenic-Sr, and depleted in $\mathrm{Al}_{2} \mathrm{O}_{3}, \mathrm{Na}_{2} \mathrm{O}, \mathrm{La}, \mathrm{Zr}$, relative to its north-eastern counterpart. The primitive signature of the southern melt, coupled with peaks in $\mathrm{SO}_{2}$ output and explosivity, suggest rapid ascent of relatively unmixed and undegassed 'eccentric' magma. As the activity continued, southern eruptions became less explosive, with a gradual shift towards central-conduit-like compositions. A corresponding shift in ${ }^{87} \mathrm{Sr} /{ }^{86} \mathrm{Sr}$ isotope ratios (0.7066 to 0.70358$)$ implies progressive mixing of isotopically distinct magmas as the main driver of the observed compositional (and eruptive) change. Compositional mapping of entire thin sections supports extensive magma mixing in the southern flank, recorded by ubiquitous reverse zoning of clinopyroxene and olivine. In contrast, the cargo erupted on the north east-rift had only minor reverse zoning. We suggest that a rechargetriggered hybrid magma was erupted on the southern flank, its melt composition and explosivity fluctuating in response to mixing between eccentric and central-conduit magmas with time. Meanwhile, the north-east flank erupted unmixed central-conduit magma escaping the effects of recharge. 